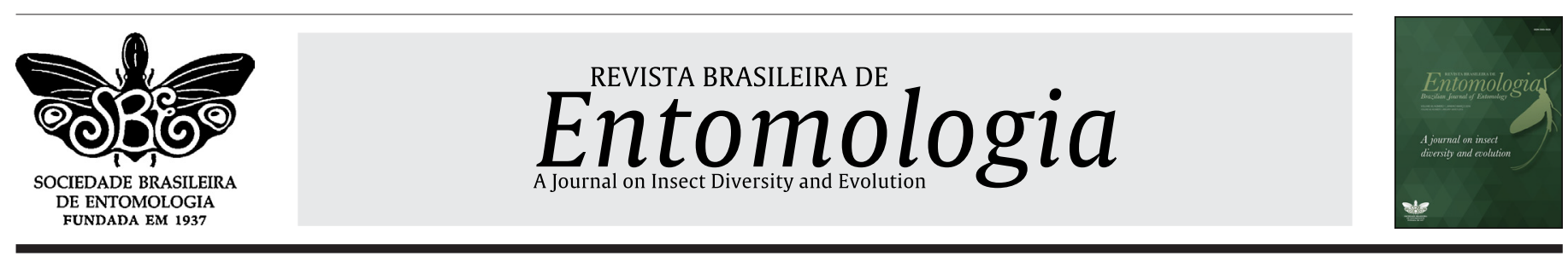

\title{
Flexibility in the integration of environmental information by Dinoponera quadriceps Kempf during foraging
}

\author{
Dina Lillia Oliveira Azevedoํㅜㄹ Jeniffer da Câmara Medeiros ${ }^{1}$, Arrilton Araújo ${ }^{1 *}$ (D) \\ ${ }^{1}$ Universidade Federal do Rio Grande do Norte, Centro de Biociências, Departamento de Fisiologia e Comportamento, Laboratório de \\ Biologia Comportamental, Programa de Pós-Graduação em Psicobiologia, Natal, RN, Brasil.
}

\section{A R T I C L E I N F O}

\section{Article history:}

Received 04 August 2021

Accepted 08 October 2021

Available online 08 November 2021

Associate Editor: Ricardo Solar

\section{Keywords:}

Ants

Ponerinae

Directionality

Route fidelity

Behavioral flexibility

\begin{abstract}
A B S T R A C T
Foraging behavior requires animals' behavioral flexibility to exhibit efficient strategies that result in the successful search for food. The navigation of ants enables long distance trips back and forth from the nest, using orientation cues. We analyzed the flexibility of Dinoponera quadriceps workers in integrating information introduced into the environment. We studied workers from two colonies in an area of secondary Atlantic Forest, with the use of a physical obstacle placed in front of the entrance of the nest with no fixed angular position. There was no significant difference in the resolution time workers to bypass the obstacle, in the angles between trips when exiting and returning to the nest, or in the positioning angles when returning to the nest. However, we found an increase in positioning angles when leaving the nest to search food, from the second contact onwards. They overcame the new obstacle as they would any other natural one. The presence of the obstacle did not prevent workers from maintaining route fidelity to individual areas. The behavior of $D$. quadriceps workers indicates that they have the flexibility to incorporate new information in a familiar environment. They likely use multimodal cues, which prevent them from wandering outside the familiar area.
\end{abstract}

\section{Introduction}

Social foraging models characterize individuals according to their behavioral decisions. These decisions occur based on economic information about the fitness consequences of alternative actions. Learning is the mechanism involved in obtaining, storing and remembering the economic information (Giraldeau and Caraco, 2000). It, implicitly, assumes the existence of memory, which is the ability to retain recently acquired information for at least a short period, but often also during long periods (Dukas, 2008).

The evolution of spatial memory processes link to the emergence of the foraging area (Benhamou and Poucet, 1996). An individual becomes familiar with an area by learning landmarks and associating them with navigation information (Collett and Collett, 2000). Local navigation is the process of moving around the immediate environment, where only objects within the range of perception are useful (Trullier et al., 1997). To avoid wasting time in a random search, the animals use two orientation systems: an associative route and a cognitive map. Since experience generally involves a spatial sequence, these systems are not mutually exclusive (Beugnon et al., 1996).

\footnotetext{
*Corresponding author.

E-mail: arrilton.araujo@ufrn.br (A. Araújo).
}

The expression of sensory processing, decision making, memories and routines involved in insect navigation occurs in the routes, search patterns and actions of insects when traveling in familiar areas. The associations among memories have a basic role in landmark recognition in the environment and the ability of insects to follow routes (Collett and Collett, 2002). Familiar terrain seems represented in two ways: the first is metric representation of the area in terms of path integration coordinates, centered on the nest, and significant local coordinates stored in long-term memory. The second are memories of landmarks linked to local vectors that provide insects with a sequence of memories that guide them along a route from the starting point to the goal (Collett and Collett, 2004).

In ants, foraging occurs so that they remain as far away as possible from the nest within the familiar territory (Gallistel, 1989; Collett and Collett, 2000). Sector fidelity preserves the investment made in learning landmarks (Collett and Collett, 2000). Landmarks show worker ants what action to perform, rather than their location within a global coordinate system. Maintaining independent systems can be a disadvantage but means that errors in the system do not propagate to another (Collett and Collett, 2004). 
Experience is an important factor in learning routes. Worker ants with multiple experiences at a feeding site do not learn best with distance, but become familiar with the routes (Narendra et al., 2007). The integration of previous experiences over long periods in Ectatomma ruidum Roger foraging behavior results of cumulative effect of multiple immediate successes, but not of a single event (Franz and Wcislo, 2003). Experienced Paraponera clavata Fabricius ants travel faster than their inexperienced ants. They may use other orientation cues besides pheromone trails, likely an orientation system based on memorized local landmark cues (Harrison et al., 1988). Strumigenys lujae Forel probably memorize the location of their nest using information based on the search route in the area (Dejean and Benhamou, 1993).

The interaction of navigation strategies gives ants the flexibility to locate resources within their travel routes. A combination of path integration, inclined deviations and landmarks in their field of view can model the stereotypical trajectories of individual ants (Collett and Collett, 2009). For instance, desert ant Cataglyphis fortis Forel is unable to learn or retain arbitrary routes that have no landmarks, despite their ability to use path integration and to learn local vectors (Collett and Collett, 2009). The flexibility of foraging behavior demonstrates that ants can make complex adjustments (Dussutour et al., 2009).

There are few studies conducted on forest species, but the subject has been widely reported in desert ants. Species of the Neotropical genus Dinoponera Roger are among the largest known ants. The distribution of the genus is restricted to South America (Kempf, 1971). Dinoponera quadriceps Kempf is a species of Ponerinae ant whose foraging behavior exhibits a route fidelity pattern and an individual core area (Azevedo et al., 2014). Its workers forage alone and do not recruit nest mates at any time (Lanan, 2014). In the Atlantic Forest, foraging activity is predominantly diurnal (Medeiros et al., 2014). The workers leave the colony with a slow movement speed and start foraging right after leaving the nest (Araújo and Rodrigues, 2006; Azevedo et al., 2014). Their Atlantic Forest habitat shows significant potential for learning orientation cues, which allow workers to overcome environmental obstacles. The aim of this study was to analyze the displacement of worker ants of this species within their familiar routes, in order to integrate information acquired in the area surrounding the nest. Our hypothesis is that workers integrate environmental information that facilitates bypassing obstacles.

\section{Material and methods}

The study took place in Floresta Nacional de Nísia Floresta (FLONA) of the Chico Mendes Institute for Conservation and Biodiversity ( $6^{\circ} 5^{\prime} \mathrm{S}, 35^{\circ} 12^{\prime} \mathrm{W}$; $60 \mathrm{~m}$ altitude), Nísia Floresta municipality, Rio Grande do Norte state, located in Northeastern Brazil. Although this region is largely dry, the coastal region exhibits seasonal variations. March-July is the rainy season and August-February the dry season. Temperatures during the rainy season fall to $20^{\circ} \mathrm{C}$ and reach $33^{\circ} \mathrm{C}$ in the dry season (Santee and Arruda, 1994).

We observed 56 different D. quadriceps (Hymenoptera: Formicidae, Ponerinae) workers from two randomly selected colonies within the area of secondary Atlantic Forest. We chose two colonies to ensure that a sufficient number of individuals to perform the analyses, there were 32 different workers from a colony and 24 different workers from other colony. Data collection focused on individuals rather than colonies, since each individual forages alone and never makes recruitment, and individual differences can contribute to colony efficiency, according to individual decision making. To allow individual identification, the workers in each colony were marked with a numbered plastic label, glued to the thorax, using a cyanoacrylate ester adhesive (Corbara et al., 1986). All individuals in the same colony had the numbered plastic label with the color of the colony. Thus, each unique label identified individuals by number and their colony by color.

The behavioral observations took place over a six-month period, from July to December. The two observers followed a worker as it left the colony until it returned. Each colony observed for at least 10 hours/ day, at least once a week from 5:30 a.m. to 5:30 p.m. We used the focal animal sampling technique (Martin and Bateson, 1994) to record behavior from the beginning to the end of foraging, regardless of whether the individual returned with or without food and latency between trips. We observed at least two consecutive trips per day for each worker.

To analyze the possibility of $D$. quadriceps workers integrating environmental information, we placed an opaque black acrylic plate $(100 \times 30 \times 0.8 \mathrm{~cm})$ along the routes they used as a physical obstacle. It placed two meters from the entrance of the nest, which is the traveled minimum distance, and it removed at the end of each observation day. The positioning of the plate changed every new observation day because workers performed activities in different directions in the area around the nest. The position of plate was so that in tracing a line from the nest to the center of the plate, it would form an angle of $90^{\circ}$ (Fig. 1). We denominated the time that each worker spent to bypass the plate as resolution time, it measured as soon as the ant left the nest until it went around the obstacle. We also recorded the direction that a worker took after surpassing the plate.

We applied the technique described by Turchin et al. (1991) to map ant displacement, with some modifications. Thus, during foraging, a numbered flag was placed every five minutes (Azevedo et al., 2014), and irrespective of this pre-established time, it placed a flag when the ant approached and/or bypassed an acrylic plate too. At the end of the observations, we measured the distance and the angle between the flags, using a compass and tape measure. These data were plotted on MóPi (software developed solely to draw the displacement of workers) to obtain an estimate of the path. From this drawing, we located the position of each flag in relation to the nest to conduct statistical tests.

With the angles obtained from the position of the numbered flags in relation to the nest, we calculated two angular distances (difference between angles) (Batschelet, 1981) used in analyses, whereby the worker reached and circumvented the plate. The first angular distance (angles between trips) referred to the difference in subsequent contacts in relation to the $1^{\text {st }}$ contact with the plate, because it was the first time that the worker encountered the new information in environment around the nest. The differences of angles between trips when searching for food and returning to the nest were analyzed as follows: A - difference between $1^{\text {st }}$ and $2^{\text {nd }}$ contact; $\mathrm{B}$ - difference between $1^{\text {st }}$ and $3^{\text {rd }}$ contact; and $\mathrm{C}$ - difference between $1^{\text {st }}$ and $4^{\text {th }}$ contact (Fig. 1 ).

The second angular distance was that between plate position and contact angles (positioning angles). It was defined as the difference between the plate position angle, which was the angle recorded from the nest towards the center of the plate and each contact angle $\left(\alpha_{1}, \alpha_{2}, \alpha_{3}\right.$ and $\left.\alpha_{4}\right)$ when the worker left the nest (Fig. 1$)$. In the return to the nest, the position angle of the acrylic plate was the angle opposite the vertex, which is the angle opposite to the central position angle described above (Fig. 1).

We observed for 183 hours the two selected colonies. With the record of 316 trips undertaken by 56 workers. We analyzed only the trips of the workers who had surpassed the obstacle, at least two and at most four times a day. In this sense, we analyzed 109 trips by 36 different workers in this study; there were 18 different workers from each colony. We compared trips towards the obstacle in resolution time, angles between trips as the angular distance when leaving and returning to the nest, and the positioning angles also as the angular distance when leaving and returning to the nest. All these analyses conducted using Kruskal-Wallis test and when necessary Mann-Whitney-Wilcoxon test 

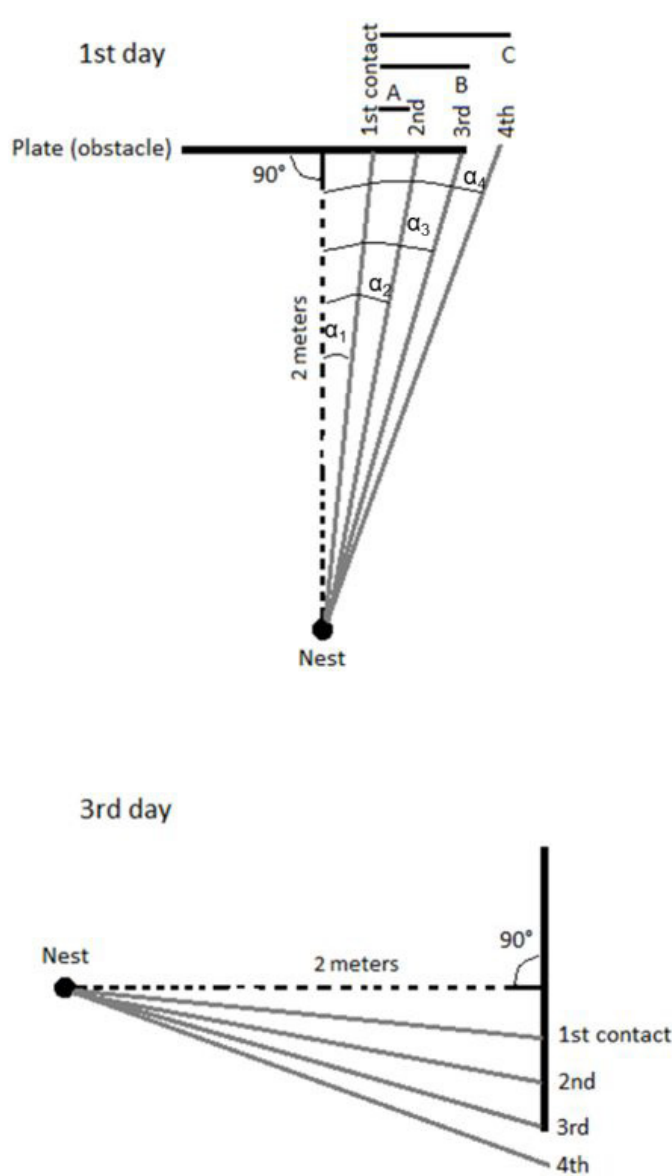

2nd day

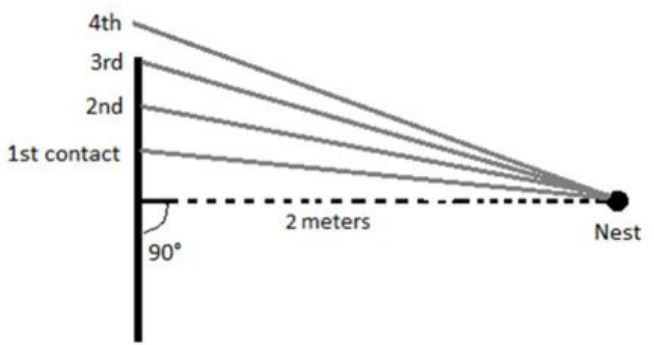

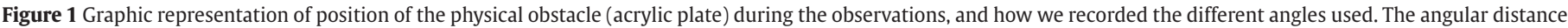

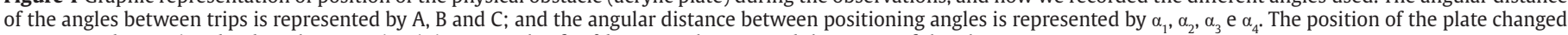
every new observation day, but always maintaining an angle of $90^{\circ}$ between the nest and the center of the plate.

with Bonferroni correction to post-hoc. We considered a $5 \%$ significance level ( $\mathrm{p} \leq 0.05$ ) for the two-tailed tests, except for the post-hoc, where significance was $0.8 \%$ ( $\mathrm{p} \leq 0.008$, due to Bonferroni correction). We used IBM SPSS Statistics 21 software (IBM Corp. Released, 2012).

\section{Results}

Trip time, distance traveled and departure latency to a new search for food varied among workers and between trips of the same workers (Table 1 ). In only $25 \%$ of these trips, they returned with a food item. In this study, when it captured a prey the D. quadriceps worker returned to the nest in a roughly linear trajectory, as described by Araújo and Rodrigues (2006) and Azevedo and collaborators (2014). However, if it did not capture a prey the worker took a zigzag path, even after hours of searching, which could delay the next trip. The time elapsed between departure from the nest until bypassing the obstacle (acrylic plate), that is resolution time, showed no significant difference among trips $\left(\mathrm{H}_{3,109}=1.55, \mathrm{p}=0.67\right)$ (Fig. 2). Although not statistically significantly, a decrease in resolution time recorded on the second trip indicates that probably the ants adjust their route.

The workers maintained the same direction on all the trips, with no significant difference in the angular distance of the angles between trips when leaving $\left(\mathrm{H}_{2,73}=1.10, \mathrm{p}=0.57\right)$ (Fig. 3a) or returning to the nest $\left(\mathrm{H}_{2,73}=2.01, \mathrm{p}=0.36\right)$ (Fig. 3b). When leaving the nest, the greatest variation was between the $1^{\text {st }}$ and $4^{\text {th }}$ trip (C). The workers did not change directional fidelity after their first contact with the obstacle (Fig. 4). Figure 4 shows as an example the trips of a single worker. After returning to the nest following the first contact ( $1^{\text {st }}$ trip), the ant adjusted its route and did not touch the acrylic plate. On the second trip, on leaving the nest the ant made an adjustment to avoid touching the obstacle, and on the third one, it touched the edge of the plate when leaving the nest, but changed its route when returning to detour around the obstacle. On the fourth and fifth trips, the ant bypassed the obstacle when both leaving and returning to the nest.

Analysis of the angular distance between plate position and contact/ bypass angles (positioning angles) after leaving the nest exhibited a statistical difference when workers left in search of food $\left(\mathrm{H}_{3,109}=20.13\right.$, $\mathrm{p}=0.01$ ) (Fig. 5a). The increase in angular distance during the second detour around $(\mathrm{U}=368.50, \mathrm{p}=0.002)$ the obstacle demonstrates that workers integrate the new information, and consequently adjust their routes to maintain directional fidelity. This adjustment was maintained in subsequent trips, even if the worker touched the obstacle again $(1-3$ : $U=277.00, p=0.019 ; 1-4: U=55.00, p=0.001 ; 2-3: U=421.00, p=0.868$; $2-4: \mathrm{U}=148.00, \mathrm{p}=0.051$ and $3-4: \mathrm{U}=95.00, \mathrm{p}=0.052$ ). 
There was no statistical difference in the return to the nest $\left(\mathrm{H}_{3,109}=1.90, \mathrm{p}=0.59\right)$ (Fig. 5b). The adjustment made when bypassing the obstacle to continue searching for food may influence the return route. The workers remained in the same area. They occasionally approached the plate before circumventing or passing beneath it, if there was space.

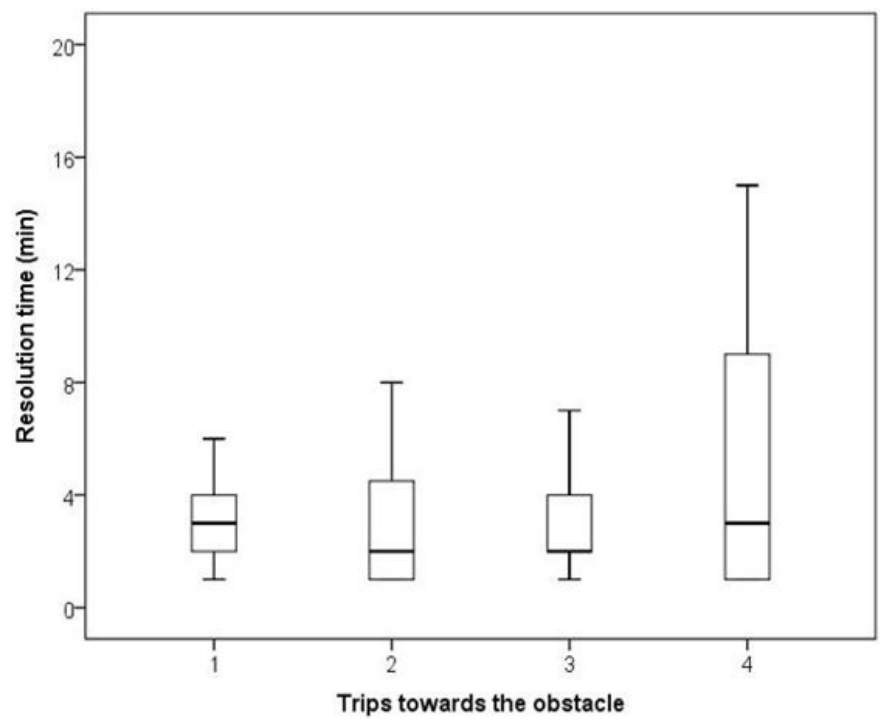

Figure 2 Median and quartiles for the resolution time of the 109 trips undertaken by 36 different workers that made contact with the acrylic plate (obstacle). Sample size of each trip toward the obstacle: $1=36 ; 2=36 ; 3=24$; and $4=13$.
Sometimes the workers touched the plate and immediately returned to the nest. Some workers developed their foraging activity without approaching the plate (we did not consider these 20 workers in the analyses). When approaching the plate, workers sometimes stopped, lifted and turned their head with antennae outstretched, proceeding towards the plate and skirting around it.

\section{Discussion}

Individual differences in distance traveled, foraging time and time between trips demonstrate that individual decision making occurs, which can influence the foraging efficiency of the colony. D. quadriceps workers explore the environment and show consistency in foraging routes, and individual foragers exhibit directional fidelity to a specific search area (Azevedo et al., 2014). These individual differences appear influenced by the availability of food in the search area of the colony, and the degree of knowledge that the workers have of the area. That depends on how familiar they are with the environment around the nest. During foraging trips, ants may follow stereotyped routes in one direction or another (Harris et al., 2005). Nevertheless, individual fidelity to a particular direction may be an extreme case of foraging behavior, previously recorded in Paltothyreus tarsatusFabricius (Hölldobler, 1980), Neoponera apicalis Latreille(Fresneau, 1985) and D. quadriceps (Azevedo et al., 2014).

The heterogeneous environment in which the nests were located requires strategies to optimize the search for food. Homogeneous prey distribution does not promote a search strategy because ants have abundant easy-to-find prey (Buchkremer and Reinhold, 2008). On the other hand, heterogeneous distribution may require workers a

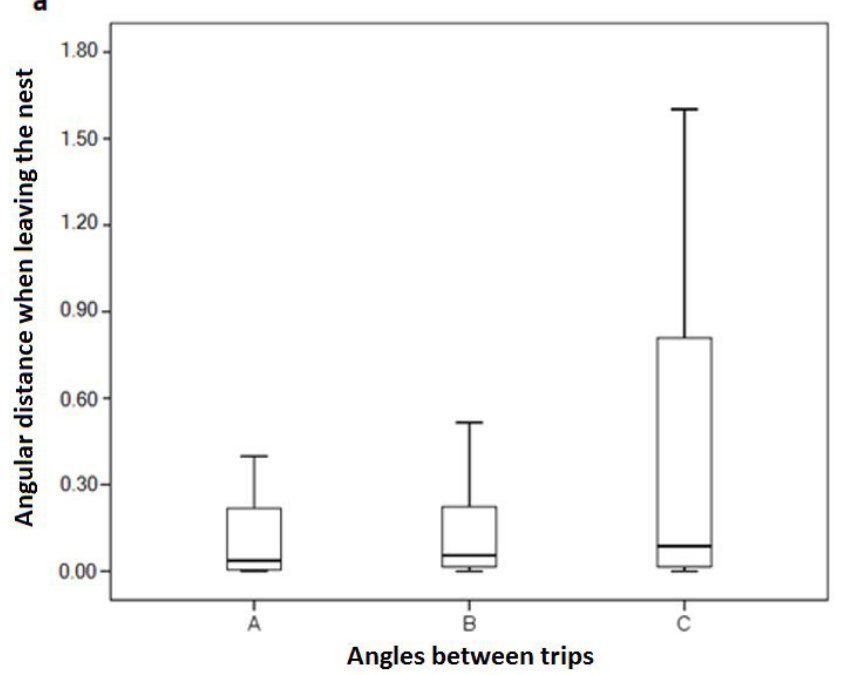

b

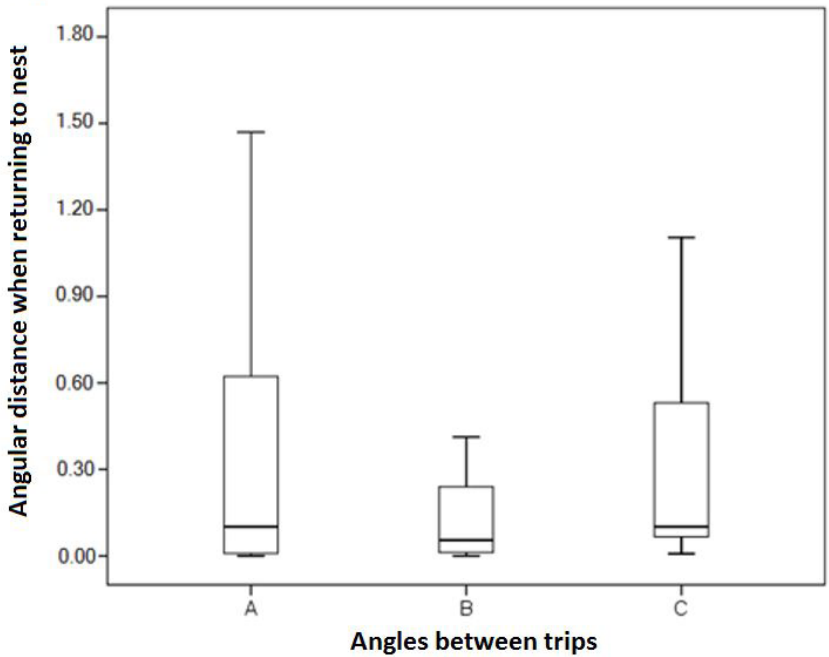

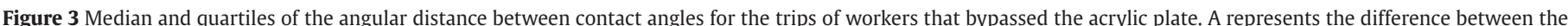

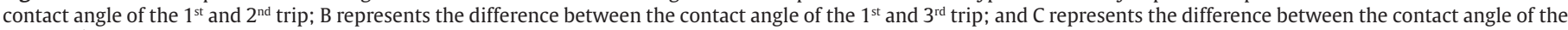
$1^{\text {st }}$ and $4^{\text {th }}$ trip. 'a' represents trips in search of food and ' $b$ ' the return to the nest.

Table 1

Variation in trip time, distance traveled and departure latency for the 316 foraging trips.

\begin{tabular}{|c|c|c|c|}
\hline \multirow{2}{*}{ Foraging variables } & \multirow{2}{*}{ Median } & Quartiles & \multirow{2}{*}{ Amplitude } \\
\hline & & $25 \%-75 \%$ & \\
\hline Departure latency (min) & 4.0 & $2.0-13.0$ & $0.0-217.0$ \\
\hline Trip time (min) & 16.5 & $4.0-48.3$ & $1.0-337.0$ \\
\hline Distance traveled $(\mathrm{cm})$ & 966.0 & $99.8-2817.3$ & $10.0-17290.0$ \\
\hline
\end{tabular}



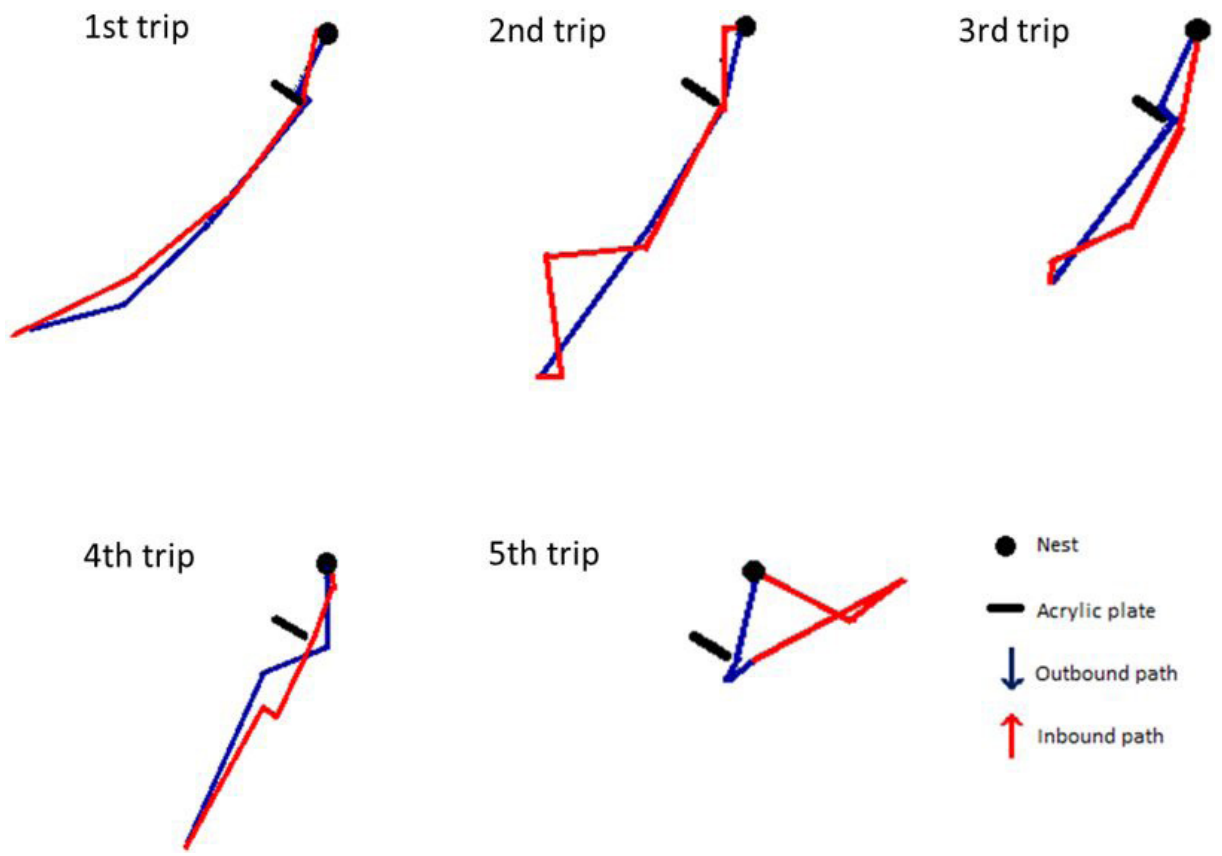

5th trip
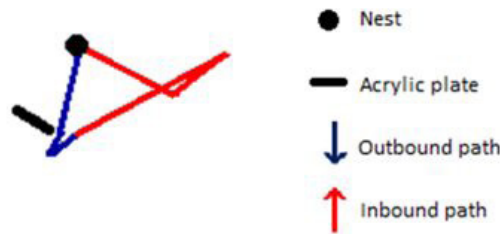

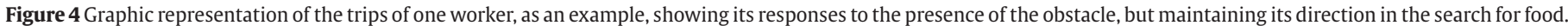
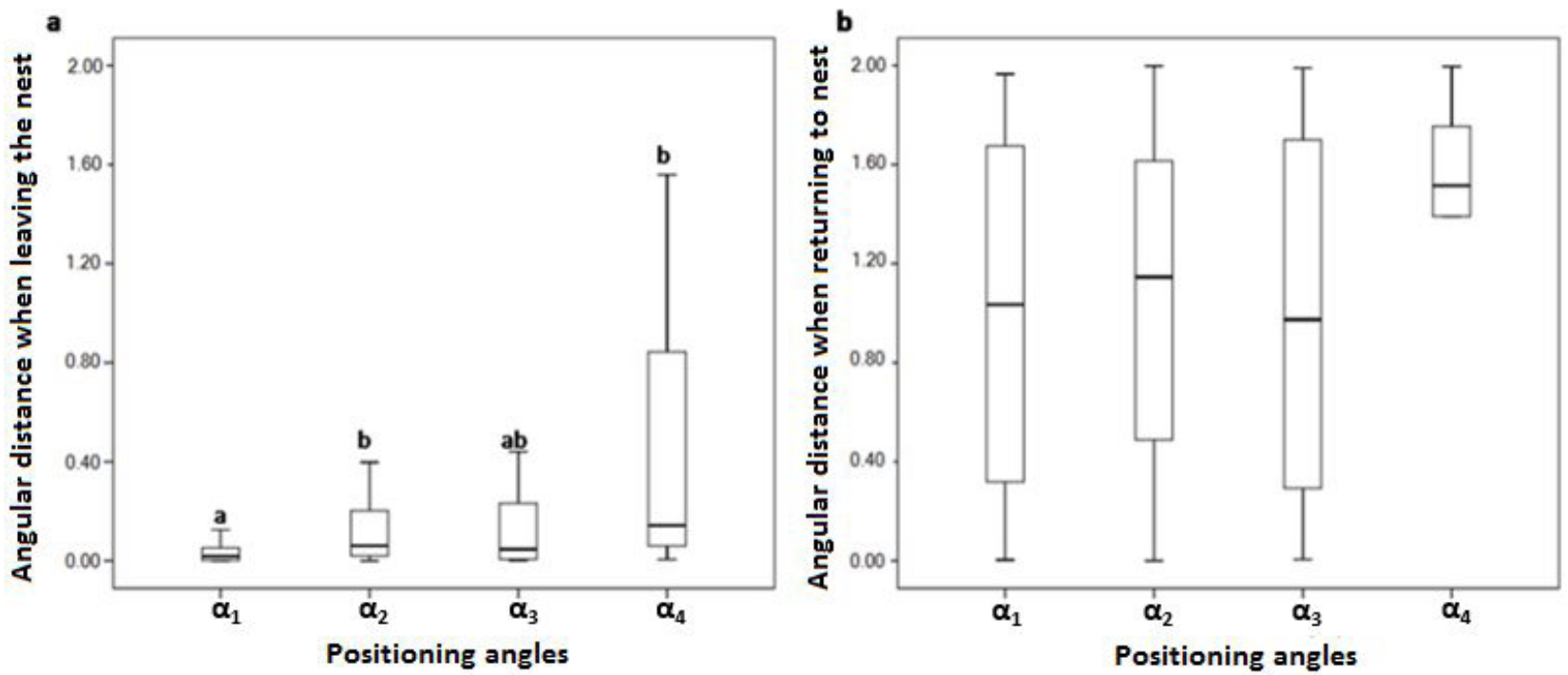

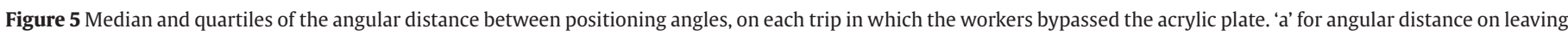
nest and 'b' for angular distance returning to the nest. Different letters indicate a statistical difference; same letters indicate no difference.

to spend part of their search time traveling to an area they know well to examine it carefully (Carroll and Janzen, 1973).

The graphic representation of $D$. quadriceps trips shows the typical behavior of all workers observed in this study. They maintain directional fidelity to the area in which they search for food and more than one worker forages in the same area. Thus, the consequences of an unsuccessful food search to the colony are less harmful than having a single worker searching in each area. Individual decisions are based on cognitive processes that can be relatively simple or highly sophisticated (Dussutour et al., 2009). Resource-related learning processes may also be involved in the persistence of route fidelity and memory (Traniello, 1989).

Two other species from this genus also show the route fidelity, $D$. gigantea Perty (Fourcassié and Oliveira, 2002) and D. australis Emery
(Tillberg et al., 2014). In the species Melophorus bagoti Lubbock, sector fidelity shows that foraging distance in a familiar area increases with the ant's experience (Muser et al., 2005). However, in Pogonomyrmex barbatus Smith $\mathrm{F}$, foraging does not require any other individual to indicate a particular location with abundant food. A system of decentralized interactions adjusts the number of foragers according to food availability (Beverly et al., 2009). Thus, strict fidelity to the foraging site and access route leads to a distinct foraging pattern for the entire colony (Fresneau, 1985).

In this study, a physical barrier placed on the foraging route of $D$. quadriceps workers resulted in different responses. The workers, who engaged in their activities closer to the nest, were apparently inexperienced and had yet to define their foraging routes. When first leaving the nest, inexperienced workers select a nearby route (Fresneau, 
1985). Apparently, D. quadriceps establishes foraging direction and distance as they become more experienced through familiarity with landmarks along the route. N. apicalis (Fresneau, 1985), E. ruidum (Franz and Wcislo, 2003), and M. bagoti (Narendra et al., 2007) show a similar route familiarization pattern.

D. quadriceps workers that bypassed the obstacle showed no significant change in resolution time or angular difference between contact/bypass angles. Nevertheless, they bypassed the plate by making minor adjustments that allowed them to maintain their routes to both the foraging area and for the return trip to the nest. The time variation was likely due to individual differences, such as worker reactions, including walking beside the plate or looking for a path beneath it. Ant species that live in tropical forests with unpredictable canopy patterns are able to learn and store images of particular branch and leaf configurations using a more subtle interaction of cognitive processes (Hölldobler, 1980). Ants probably acquire most of their knowledge of landmarks while they are relatively close to the nest or on fixed routes, rather than during extensive spatial exploration (Collett et al., 2007).

The variation in angular distance between trips shows an increasing trend, which is another indication that workers adjust their route. Sector fidelity supplies foragers with knowledge about familiar landmarks (Collett and Collett, 2000). D. quadriceps workers likely use more than one type of orientation cue for displacement; even if new environmental information arises, they learn to overcome possible obstacles. Several ant species learn and follow routes while being visually guided when they forage (Graham and Collett, 2006).

The angular distance between plate position and contact/bypass angle increases after the $D$. quadriceps workers' first contact with the obstacle. These results corroborate those observed for the angular difference of the contact angles, demonstrating that workers do not change direction in their search for food or when returning to the nest, except for slight adjustments. This may explain why the time spent bypassing it did not vary significantly after the initial contact. The adjustment in direction has no effect on time.

The foragers acquire the information through individual learning by their interaction with the environment and the available resources (Collett, 1996). The pauses that $D$. quadriceps workers made when approaching the plate, where they lifted and turned their head with antennae outstretched before moving towards it, seem to be saccadelike body turns that allow them to change direction (Collett et al., 2014). The acrylic plate was probably perceived by $D$. quadriceps workers as new information, and they responded as they would to a natural obstacle they might encounter during daily foraging, such as a trunk or fallen branch.

\section{Conclusion}

Our results corroborate our hypothesis that workers can integrate information of the environment that facilitates bypassing obstacles. That demonstrates the worker ants' flexibility in adjusting their direction when they encounter a new obstacle. $D$. quadriceps responds to changes in the environmental context along its familiar route, through the integration of new information, making the individual work efficient and consequently, the colony's also. Probably, it related to an orientation system that can use more than one type of cue to keep them within the same familiar area. It would be interesting to find out what type of orientation cues they use to maintain efficient foraging activity.

\section{Acknowledgments}

We thank Marconi C. Rodrigues for the software developed to draw ant displacement (MóPi), Maria de Fátima Arruda for critical reading and the Universidade Federal do Rio Grande do Norte for logistical support. We are also grateful to the Chico Mendes Institute for Biodiversity (ICMBio) for the collection license (License no. 10602-1 and 12547-1), the FLONA of Nísia Floresta/RN for logistical support. In addition, we thank the National Council for Scientific and Technological Development (CNPq) (Grants 302012/2006-0 and 401738/2007-8), Coordination for the Improvement of Higher Education Personnel (CAPES) (PNPD-CAPES Grant 20130304), Research Support Foundation for Rio Grande do Norte State (FAPERN) (PRONEX Proc. MCT-01.0009-00/2002) and Research Support Foundation for Bahia state (FAPESB) (PRONEX FAPESB-CNPq PNX 0011-2009) for financial assistance.

\section{Conflicts of interest}

The authors state that there is no competing interest.

\section{Author contribution statement}

DLOA and AA planned the work. DLOA and JCM executed the work. DLOA and AA conducted data analyses. DLOA, JCM and AA wrote and revised the manuscript.

\section{References}

Araújo, A., Rodrigues, Z., 2006. Foraging behaviour of the queenless ant Dinoponera quadriceps Santschi (Hymenoptera: formicidae). Neotrop. Entomol. 35, 159-164.

Azevedo, D. L. O., Medeiros, J. C., Araújo, A., 2014. Adjustments in the time, distance and direction of foraging in Dinoponera quadriceps workers. J. Insect Behav. 27, 177-191.

Batschelet, E., 1981. Circular Statistics in Biology, 1st ed. Academic Press, London.

Benhamou, S., Poucet, B., 1996. A comparative analysis of spatial memory processes. Behav. Processes 35, 113-126.

Beugnon, G., Pastergue-Ruiz, I., Schatz, B., Lachaud, J.-P., 1996. Cognitive approach of spatial and temporal information processing in insects. Behav. Processes 35, 55-62.

Beverly, B. D., McLendon, H., Nacu, S., Holmes, S., Gordon, D. M., 2009. How site fidelity leads to individual differences in the foraging activity of harvester ants. Behav. Ecol. 20, 633-638.

Buchkremer, E. M., Reinhold, K., 2008. Sector fidelity - an advantageous foraging behavior resulting from a heuristic search strategy. Behav. Ecol. 19, 984-989.

Carroll, C. R., Janzen, D. H., 1973. Ecology of foraging by ants. Annu. Rev. Ecol. Syst. 4, 231-257.

Collett, T. S., 1996. Insect navigation en route to the goal: multiple strategies for use of landmarks. J. Exp. Biol. 199, 227-235.

Collett, M., Collett, T. S., 2000. How do insects use path integration for their navigation? Biol. Cybern. 83, 245-259.

Collett, T. S., Collett, M., 2002. Memory use in insect visual navigation. Nature 3, 542-552.

Collett, T. S., Collett, M., 2004. How do insects represent familiar terrain? J. Physiol. Paris 98, 259-264.

Collett, T. S., Graham, P., Harris, R. A., 2007. Novel landmark-guided routes in ants. J. Exp. Biol. 210, 2025-2032.

Collett, M., Collett, T. S., 2009. The learning and maintenance of local vectors in desert ant navigation. J. Exp. Biol. 212, 895-900.

Collett, T. S., Lent, D. D., Graham, P., 2014. Scene perception and the visual control of travel direction in navigating wood ants. Philos. T. R. Soc. B. 369, 20130035. 
Corbara, B., Fresneau, D., Lachaud, J.-P., Leclerc, Y., Goodall, G., 1986. An automated photographic technique for behavioural investigations of social insects. Behav. Processes 13, 237-249.

Dejean, A., Benhamou, S., 1993. Orientation and foraging movements in a patchy environment by the ant Serrastrumalujae (formicidaemyrmicinae). Behav. Processes 30, 233-244.

Dukas, R., 2008. Evolutionary biology of insect learning. Annu. Rev. Entomol. 53, 145-160.

Dussutour, A., Deneubourg, J.-L., Beshers, S., Fourcassié, V., 2009. Individual and collective problem-solving in a foraging context in the leaf-cutting ant Atta colombica. Anim. Cogn. 12, 21-30.

Fourcassié, V., Oliveira, P. S., 2002. Foraging ecology of the giant Amazonian ant Dinoponera gigantea (Hymenoptera, Formicidae, Ponerinae): activity schedule, diet and spatial foraging patterns. J. Nat. Hist. 36, 2211-2227.

Franz, N. M., Wcislo, W. T., 2003. Foraging behavior in two species of Ectatomma (Formicidae: Ponerinae): individual learning of orientation and timing. J. Insect Behav. 16, 381-410.

Fresneau, D., 1985. Individual foraging and path fidelity in a Ponerine ant. Insectes Soc. 32, 109-116.

Gallistel, C. R., 1989. Animal cognition: the representation of space, time and number. Annu. Rev. Psychol. 40, 155-189.

Giraldeau, L.-A., Caraco, T., 2000. Social Foraging Theory, 1st ed. Princeton University Press, Princeton, New Jersey.

Graham, P., Collett, T. S., 2006. Bi-directional route learning in wood ants. J. Exp. Biol. 209, 3677-3684.

Harris, R. A., Hempel de Ibarra, N., Graham, P., Collett, T. S., 2005. Priming of visual route memories. Nature 438, 302.

Harrison, J. F., Fewell, J. H., Stiller, T. M., Breed, M. D., 1988. Effects of experience on use of orientation cues in the giant tropical ant. Anim. Behav. 37, 869-871.

Hölldobler, B., 1980. Canopy orientation: a new kind of orientation in ants. Science $210,86-88$.
IBM Corp. Released, 2012. IBM SPSS Statistics for Windows, Version 21.0, Armonk, New York.

Kempf, W. W., 1971. A preliminary review of the Ponerinae ant genus Dinoponera Roger (Hymenoptera: formicidae). Stud. Entomol. 14, 369-394.

Lanan, M., 2014. Spatiotemporal resource distribution and foraging strategies of ants (Hymenoptera: formicidae). Myrmecol. News 20, 53-70.

Martin, P., Bateson, P., 1994. Measuring Behaviour: An Introductory Guide, 3rd ed. Cambridge University Press, Cambridge.

Medeiros, J., Azevedo, D. L. O., Santana, M. A. D., Lopes, T. R. P., Araújo, A., 2014. Foraging activity rhythm of the queenless ant, Dinoponera quadriceps, in its natural environment. J. Insect Sci. 14, 220. https:// doi.org/10.1093/jisesa/ieu082.

Muser, B., Sommer, S., Wolf, H., Wehner, R., 2005. Foraging ecology of the thermophilic Australian desert ant, Melophorus bagoti. Aust. J. Zool. 53, 301-311.

Narendra, A., Cheng, K., Wehner, R., 2007. Acquiring, retaining and integrating memories of the outbound distance in the Australian desert ant Melophorus bagoti. J. Exp. Biol. 210, 570-577.

Santee, D. P., Arruda, M. F., 1994. The Nísia Floresta Common Marmoset Research Station. Neotrop. Primates 2, 8-11.

Tillberg, C. V., Edmonds, B., Freauff, A., Hanish, P. E., Paris, C., Smith, C. R., Tsutsui, N. D., Wills, B. D., Wittman, S. E., Suarez, A. V., 2014. Foraging ecology of the tropical giant hunting ant Dinoponera australis (Hymenoptera: Formicidae) - evaluating mechanisms for high abundance. Biotropica 46, 229-237.

Traniello, J. F. A., 1989. Foraging strategies of ants. Annu. Rev. Entomol. 34, 191-210.

Trullier, O., Wiener, S. I., Berthoz, A., Meyer, J.-A., 1997. Biologically based artificial navigation systems: review and prospects. Prog. Neurobiol. 51, 483-544.

Turchin, P., Odendall, F. J., Rausher, M. D., 1991. Quantifying insect movement in the field. Environ. Entomol. 20, 955-963. 